\title{
The influence of dopamine beta-hydroxylase gene polymorphism c.-979t>c (rs I6IIIII5) on the clinical manifestations of migraine
}

\begin{abstract}
Genetic factors definitely contribute to the aetiology and pathogenesis of migraine. A number of others studies have been conducted to better define genetic predisposition to dopamine metabolism disorders. The objective we had in this study was to evaluate the effect of the $\mathrm{C}$ and $\mathrm{T}$ alleles of DBH gene polymorphism rs1611115 (c.-979T $>\mathrm{C}$ ) on the clinical characteristics of migraine. The retrospective study included 132 patients with migraine and control group included 348 unexamined subjects (population control), all living in Moscow and Moscow region. Genotypes were identified by PCR-RFLP method using FauI endonuclease. We demonstrated the role played by polymorphism at the promoter region of the DBH gene (rs1611115, allele T) in the development of the following clinical characteristics of migraine $(p<0.05)$ : allodynia, prodrome, postdrome, vomiting, aura, and the number of taken drugs. The data we obtained confirm the involvement of the dopaminergic system in the pathogenesis of migraine, particularly at the attack initiation stage.
\end{abstract}

Keywords: Migraine, Clinical characteristics, DBH gene, SNV, rs1611115
Volume 8 Issue I - 2018

\author{
Eugene Klimov, ${ }^{1,2}$ Kirill Skorobogatykh, ${ }^{3}$ \\ Olga Rudko,' Elena Naumova,' Natalia \\ Kondratieva,' Julia Azimova, ${ }^{3}$ Alexey \\ Sergeev, ${ }^{3,4}$ Zarema Kokaeva,' Gyuzya \\ Tabeeva ${ }^{3,5}$ \\ 'Faculty of Biology of Lomonosov Moscow State University, \\ Russia \\ ${ }^{2}$ University diagnostic laboratory, Russia \\ ${ }^{3}$ University Headache Clinic, Russia \\ ${ }^{4}$ Department of Neuroscience, IM Sechenov First Moscow State \\ Medical University, Russia \\ ${ }^{5}$ Department of neurology and neurosurgery, IM Sechenov First \\ Moscow State Medical University, Russia
}

\author{
Correspondence: Eugene Klimov, Department of Genetics, \\ Biological Faculty of Lomonosov Moscow State University, \\ 1 1 9234, Lenin Hills, 1-12, Moscow, Russia; \\ Email klimovㄱ_eugeney@mail.ru
}

Received: September 21, 2017 | Published: January 30, 2018

\section{Introduction}

Genetic factors definitely contribute to the aetiology and pathogenesis of migraine. In the last decade, great interest has been shown in genetic research in patients with migraine. ${ }^{1}$ Significant success has been achieved, and genes responsible for the development of various forms of familial hemiplegic migraine have been identified. ${ }^{2}$ A number of others studies have been conducted to better define genetic predisposition to dopamine metabolism disorders. The first study in this field was published in 1997, revealing the DRD2 (D2 dopamine receptor) gene polymorphism, which was found to be significantly more common in patients suffering from migraine with aura. ${ }^{3}$ Subsequent studies broadened the scope of searching for potential research targets. All five receptor types were examined, and the next series of experiments failed to confirm changes in the D2DR gene; conflicting data were obtained on the D4 receptor. A study conducted by Todt in 2009 demonstrated that certain alleles of the gene encoding the dopamine transporter SLC6A3 were reliably associated with migraine with aura. ${ }^{4}$ This transporter is responsible for reuptake of dopamine from the synaptic cleft, thus acting as a key regulator of dopaminergic activity. Most completed genetic studies have confirmed the role of polymorphism of the gene encoding the enzyme dopamine beta-hydroxylase (DBH), which stimulates the conversion of dopamine to norepinephrine. ${ }^{5-8}$

Several SNPs found in the DBH gene were significantly more frequent in patients with migraine, and rs1611115 (often referred to as "-1021C/T" in literature sources), which is located in the promoter region, is the most interesting of them. The replacement of $\mathrm{C}$ with $\mathrm{T}$ changes the transcriptional activity of the gene and decreases plasma DBH levels. T allele homozygotes have the lowest plasma activity of $\mathrm{DBH}^{9-13}$ Some data were published recently demonstrating that patients with episodic or chronic migraine have increased plasma dopamine concentrations. ${ }^{14}$ which may be associated with lower activity of the DBH gene. The objective we had in this study was to evaluate the effect of the $\mathrm{C}$ and $\mathrm{T}$ alleles of $\mathrm{DBH}$ gene polymorphism rs1611115 (c.-979T >C) on the clinical characteristics of migraine.

\section{Materials and Methods}

The retrospective study included 132 patients with migraine living in Moscow and Moscow region, with a mean age of $41.6 \pm 12.5$ years. All those patients primarily visited the specialized University Headache Clinic (Moscow) for headache in the years 2012-2015.

The inclusion criteria were:

i. Migraine (chronic migraine according to the International Classification of Headaches III (ICHD-III), 2013). ${ }^{15}$

ii. Age 18-69 years.

iii. The exclusion criteria were:

iv. Probable migraine, according to the ICHD-III;

v. Familial or sporadic hemiplegic migraine, according to the ICHD-III;

vi. Significant medical conditions other than migraine;

vii. Actual chronic migraine risk factor (current evidence of depression based on a Beck Depression Inventory (BDI) total score $>19$, sleep disorders, stressful life events, caffeine overuse);

viii. Any prophylactic treatment for migraine for at least 3 months prior to the study. 
Migraine was diagnosed by experienced neurologists based on the criteria of the ICHD-III. The patients were interviewed regarding the disease duration, the type of migraine, the frequency of migraine attacks (for the last 3 months), drugs used, underwent a clinical neurological examination and blood sampling for genotyping. The study was approved by the local ethics committee and all subjects gave informed consent to participate in the study. The control group included 348 unexamined subjects (population control), inclusion criteria: place of residence in Moscow or Moscow region. Patients and controls were age-matched. The study was conducted according to the Declaration of Helsinki Principles.

\section{Molecular genetic testing and data analysis}

The DNA extraction was performed according to the protocol for the DNA Magna ${ }^{\mathrm{TM}}$ DNA Prep 200 commercial kit (Isogene Laboratory LLC, Moscow, Russia). Genotypes were identified by PCR-RFLP method. The PCR was conducted according to the protocol for the HS Taq DNA polymerase mix (Evrogen Company, Moscow, Russia). Primers were synthesized by DNA Synthesis, LLC (Moscow, Russia): F: CTAGTCCAGCTGGAGAGATCT and R: TTTGCCATCATCCACCCGTG. PCR conditions included initial denaturation $\left(94{ }^{\circ} \mathrm{C}\right.$ for $\left.3 \mathrm{~min}\right)$, followed by 40 cycles consisting of denaturation $\left(95^{\circ} \mathrm{C}\right.$ for $\left.20 \mathrm{~s}\right)$, primer annealing $\left(61^{\circ} \mathrm{C}\right.$ for $\left.10 \mathrm{~s}\right)$, chain elongation $\left(72^{\circ} \mathrm{C}\right.$ for $\left.15 \mathrm{~s}\right)$, the reaction is completed with the final elongation $\left(72^{\circ} \mathrm{C}\right.$ for $\left.5 \mathrm{~min}\right)$. The restriction endonuclease FauI produced by SibEnzyme Ltd. (Novosibirsk, Russia) was used for digestion; the reaction was carried out under conditions recommended by the manufacturer. Restriction product size: $\mathrm{CC}=89+77, \mathrm{CT}=166+89+77, \mathrm{TT}=166$. Products of restriction were separated in $2 \%$ agarose gel. Statistical analysis was performed using the Fisher test and Pearson's chi-squared test available in the WinPePi application package and using Student's test, with the help of the MS Excel (2010) software package. Results were regarded as significant at $\mathrm{p}<0.05$.

\section{Results}

The following rates of alleles and genotypes were obtained in the study population (subjects / control): C $-0.715 / 0.745, \mathrm{~T}-0.285 /$ 0.255 ; CC $-0.514 / 0.582$; CT $-0.402 / 0.326$; TT $-0.084 / 0.092$. The distribution of genotype frequencies for rs 1611115 in the study groups corresponded to Hardy-Weinberg equilibrium (patients: $\chi 2$ $=0.0, \mathrm{p}=0.95$; control: $\left.\chi^{2}=3.49, \mathrm{p}=0.06\right)$. We did not find any significant difference in the frequencies of studied alleles $(\chi 2=0.969$, $\mathrm{p}=0.325)$ and genotypes $(\chi 2=1.710, \mathrm{p}=0.191)$ between patients and controls and therefore concluded that generally there is no association between the studied SNV and migraine. The genotype frequencies and the clinical characteristics of study subjects are presented in Table 1.

Table I Representation of the clinical characteristics of migraine in the study sample and the rates of the rs I6I I I I 5 replacement genotypes of the DBH gene. Statistically significant differences are shown in bold. Analysis of the association in the samples: control / group of patients having the symptom

\begin{tabular}{|c|c|c|c|}
\hline & \multicolumn{2}{|l|}{ Genotype } & \multirow{2}{*}{ Fisher's P (Two-Tailed) } \\
\hline & cc & CT+TT & \\
\hline Controls $(n=363)$ & 209 & 153 & 02 \\
\hline Migraine $(n=146)$ & 75 & 71 & 0.2 \\
\hline \multicolumn{4}{|l|}{ Symptom } \\
\hline Females $(n=120)$ & 0.85 & 0.9 & 0.09 \\
\hline Age at onset & $17.28 \pm 2.16$ & $18.82 \pm 2.26$ & $0.169 *$ \\
\hline Aura $(n=25)$ & 0.14 & 0.24 & 0.038 \\
\hline Chronic $(n=44)$ & 0.31 & 0.37 & 0.155 \\
\hline Episodic $(n=96)$ & 0.69 & 0.63 & 0.406 \\
\hline Therapy-resistant $(n=20)$ & 0.13 & 0.17 & 0.354 \\
\hline Abuse $(n=46)$ & 0.32 & 0.35 & 0.21 \\
\hline Number of drugs (tablets) & $24.27 \pm 9.30$ & $42.66 \pm 18.34$ & $0.049 *$ \\
\hline Frequency of attacks & $8.49 \pm 2.43$ & $8.79 \pm 2.44$ & $0.432 *$ \\
\hline Attack duration, hours & $33.16 \pm 6.43$ & $37.19 \pm 6.70$ & $0.200 *$ \\
\hline Headache worsening time, minutes & $101.28 \pm 22.84$ & $94.79 \pm 22.33$ & $0.346 *$ \\
\hline VAS headache intensity & $8.21 \pm 0.37$ & $8.53 \pm 0.35$ & $0.108^{*}$ \\
\hline Nausea $(n=\mid 16)$ & 0.89 & 0.92 & 0.054 \\
\hline Vomiting $(n=60)$ & 0.42 & 0.51 & 0.049 \\
\hline Photophobia $(n=\mid 10)$ & 0.89 & 0.83 & 0.156 \\
\hline Phonophobia $(n=108)$ & 0.87 & 0.82 & 0.185 \\
\hline Osmophobia $(n=65)$ & 0.5 & 0.52 & 0.138 \\
\hline Allodynia $(n=57)$ & 0.39 & 0.56 & 0.015 \\
\hline Throbbing pain $(\mathrm{n}=99)$ & 0.77 & 0.77 & 0.11 \\
\hline Prodrome $(n=43)$ & 0.29 & 0.45 & 0.014 \\
\hline Postdrome $(n=34)$ & 0.25 & 0.36 & $0.03 I$ \\
\hline
\end{tabular}

* - calculation performed using Student's t-test for independent samples; analysis within the sample.

The CT+TT genotypes were found to be associated with the following clinical characteristics of migraine (the T allele is inherited in a dominant fashion):
i. Number of taken drugs
ii. Aura (OR=2.43, CI95\% [0.98-6.40]),

iii. Vomiting (OR=1.79, CI95\% [0.99-3.24]),

iv. Allodynia (OR=2.02, CI95\% [1.10-3.74]),

v. Prodrome $(\mathrm{OR}=2.31, \mathrm{CI} 95 \%$ [1.15-4.74]),

vi. Postdrome $(\mathrm{OR}=2.21, \mathrm{CI} 95 \%$ [1.02-4.95]). 


\section{Discussion}

Previous studies have demonstrated a connection between DBH gene polymorphism and migraine. ${ }^{4-8,16,17}$ This study showed for the first time a reliable association between the c.-979T $>$ C polymorphism in the promoter region of the DBH gene and certain clinical characteristics of migraine. The $\mathrm{T}$ allele has a negative effect on the transcriptional activity of the DBH gene, thus decreasing the amount of the enzyme.

The relationship between the $\mathrm{T}$ allele carrier state and aura that we identified is difficult to explain at the moment. So it is known that dopamine levels in platelets are higher in migraine patients than in controls but only in migraine without aura. ${ }^{18}$ And migraine with aura is associated with another polymorphism in DBH gene (rs2097629). ${ }^{4,19}$ The significantly higher occurrence of allodynia in carriers of the $\mathrm{T}$ allele should be underlined. In patients with migraine, allodynia is known to be a marker of central sensitization. ${ }^{20}$ The presence of the T allele heightens the level of central sensitization, possibly as a result of less intense inhibition exerted by dopaminergic pathways on the trigeminocervical complex. Prodromal symptoms of migraine are largely related, or at least correspond, to the symptoms of dopamine receptor activation. In this study, we observed a reliable association between the prodromal and postdromal phases of a migraine attack in sufferers and the presence of the $\mathrm{T}$ allele in their genotype. One possibility is that the decreased amount of the enzyme leads to an increase in the dopamine concentration, which may trigger the prodromal period and worsen the postdromal phase. A number of studies have demonstrated that certain polymorphisms of the DBH gene are closely related to addictions, such as cocaine and opiate dependences. ${ }^{21-23}$ The relationship between the $\mathrm{T}$ allele carrier state and the number of drugs taken to relieve an attack, which we identified in this study, provides evidence that the pathophysiology observed in patients who take numerous medicinal products has common mechanisms with addictions rather than with pain intensity.

\section{Conclusion}

In conclusion, we demonstrated for the first time the role played by polymorphism at the promoter region of the DBH gene (rs1611115, allele T) in the development of the following clinical characteristics of migraine: allodynia, prodrome, postdrome, vomiting, aura, and the number of taken drugs. The data we obtained confirm the involvement of the dopaminergic system in the pathogenesis of migraine, particularly at the attack initiation stage.

\section{Acknowledgements}

The authors thank the subjects for their participation in this research study.

\section{Conflicts of interest}

No conflict of interest. This research received no specific grant from any funding agency in the public, commercial, or not-for-profit sectors.

\section{References}

1. Kondratieva N, Azimova J, Skorobogatykh K et al. Biomarkers of migraine: Part 1 - Genetic markers. J Neurol Sci. 2016;369:63-76.

2. Russell MB, Ducros A Sporadic and familial hemiplegic migraine: pathophysiological mechanisms, clinical characteristics, diagnosis, and management. The Lancet Neurology 2011;10(5):457-470.

3. Peroutka SJ, Wilhoit T, Jones $\mathrm{K}$ Clinical susceptibility to migraine with aura is modified by dopamine D2 receptor (DRD2) NcoI alleles. Neurology. 1997;49(1):201-206.

4. Todt $\mathrm{U}$, Netzer $\mathrm{C}$, Toliat $\mathrm{M}$ et al. New genetic evidence for involvement of the dopamine system in migraine with aura. Human genetics. 2009;125(3):265-279.

5. Lea RA, Dohy A, Jordan K Griffiths LR Evidence for allelic association of the dopamine beta-hydroxylase gene (DBH) with susceptibility to typical migraine. Neurogenetics. 2000;3(1):35-40.

6. Fernandez F, Colson N, Quinlan S et al. Association between migraine and a functional polymorphism at the dopamine beta-hydroxylase locus. Neurogenetics. 2009;10(3):199-208.

7. Fernandez F, Lea RA, Colson NJ Association between a 19 bp deletion polymorphism at the dopamine beta-hydroxylase (DBH) locus and migraine with aura. J Neurol Sci. 2006;251(1-2):118-123.

8. Ghosh J, Pradhan S, Mittal B Role of dopaminergic gene polymorphisms (DBH 19 bp indel and DRD2 Nco I) in genetic susceptibility to migraine in North Indian population. Pain medicine. 2011;12(7):1109-1111.

9. Zabetian CP, Anderson GM, Buxbaum SG et al. A quantitative-trait analysis of human plasma-dopamine beta-hydroxylase activity: evidence for a major functional polymorphism at the DBH locus. Am J Hum Genet. 2001;68(2):515-522.

10. Zabetian CP, Buxbaum SG, Elston RC et al. The structure of linkage disequilibrium at the DBH locus strongly influences the magnitude of association between diallelic markers and plasma dopamine beta-hydroxylase activity. American journal of human genetics. 2003;72(6):1389-1400.

11. Kohnke MD, Zabetian CP, Anderson GM et al. A genotype-controlled analysis of plasma dopamine beta-hydroxylase in healthy and alcoholic subjects: evidence for alcohol-related differences in noradrenergic function. Biological psychiatry. 2002;52(12):1151-1158.

12. Bhaduri N, Mukhopadhyay K Correlation of plasma dopamine betahydroxylase activity with polymorphisms in DBH gene: a study on Eastern Indian population. Cellular and molecular neurobiology. 2008;28(3):343-350.

13. Kosten TR, Wu G, Huang W, Harding MJ, Hamon SC, et al. Pharmacogenetic randomized trial for cocaine abuse: disulfiram and dopamine beta-hydroxylase. Biological psychiatry. 2013;73(3):219-224.

14. D'Andrea G, D'Amico D, Bussone G, Bolner A, Aguggia M, et al. The role of tyrosine metabolism in the pathogenesis of chronic migraine. Cephalalgia. 2013;33(11):932-937.

15. Headache Classification Committee of the International Headache $\mathrm{S}$ The International Classification of Headache Disorders, 3rd edition (beta version). Cephalalgia. 2013;33(9):629-808.

16. Ghosh J, Pradhan S, Mittal B Identification of a novel ANKK1 and other dopaminergic (DRD2 and DBH) gene variants in migraine susceptibility. Neuromolecular medicine. 2013;15(1):61-73.

17. Sezer S, Kurt S, Ates O Analysis of dopamine beta hydroxylase gene polymorphisms in migraine. Clinical neurology and neurosurgery. 2016;145:96-100.

18. D'Andrea G, Granella F, Perini F et al. Platelet levels of dopamine are increased in migraine and cluster headache. Headache. 2006;46(4):585-591.

19. Corominas R, Ribases M, Camina M et al. Two-stage case-control association study of dopamine-related genes and migraine. $B M C$ medical genetics. 2009;10:95.

20. Noseda R, Burstein R Migraine pathophysiology: anatomy of the trigeminovascular pathway and associated neurological symptoms, cortical spreading depression, sensitization, and modulation of pain. Pain 154 Suppl 12013:S44-S53. 
21. Freire MT, Marques FZ, Hutz MH et al. Polymorphisms in the DBH and DRD2 gene regions and smoking behavior. European archives of psychiatry and clinical neuroscience. 2006;256(2):93-97.

22. Liu S, Green CE, Lane SD et al. The influence of dopamine beta-hydroxylase gene polymorphism rs1611115 on levodopa/ carbidopa treatment for cocaine dependence: a preliminary study. Pharmacogenetics and genomics. 2014;24(7):370-373.
23. Xie $\mathrm{X}, \mathrm{Xu} \mathrm{L}$, Liu $\mathrm{H}$ et al. Positive association between-1021TT genotype of dopamine beta hydroxylase gene and progressive behavior of injection heroin users. Neuroscience letters. 2013;541:258-262. 